Journal Club

Editor's Note: These short, critical reviews of recent papers in the Journal, written exclusively by graduate students or postdoctoral fellows, are intended to summarize the important findings of the paper and provide additional insight and commentary. For more information on the format and purpose of the Journal Club, please see http://www.jneurosci.org/misc/ifa_features.shtml.

\title{
Mice with Reduced Vesicular Monoamine Storage Content Display Nonmotor Features of Parkinson's Disease
}

\author{
Anthony C. Vernon \\ Department of Neuroscience, King's College London, London SE5 9NU, United Kingdom \\ Review of Taylor et al.
}

Parkinson's disease (PD) is a debilitating neurodegenerative disorder affecting $\sim 1 \%$ of the population aged $>65$. Although the motor symptoms of PD are well defined, PD has a significant nonmotor component, including neuropsychiatric symptoms (depression, anxiety, dementia, cognitive dysfunction), sleep disorders, autonomic dysfunction, gastrointestinal (GI) dysfunction, and pain (Chaudhuri and Schapira, 2009). The nonmotor component of PD is often under-recognized and undertreated and can have a serious impact on patient quality of life. Management of nonmotor symptoms therefore represents a serious unmet medical need in PD (Langston, 2006). Importantly, nonmotor symptoms of PD occur not only in advanced disease, but also in early stages. Indeed, it is suggested that olfactory dysfunction, constipation, rapid eye movement (REM) sleep behavior disorder (RBD), and depression might precede the onset of motor symptoms by $5-10$ years (Chaudhuri and Schapira, 2009). Thus, nonmotor symptoms of PD may offer a means to identify individuals "at risk" of developing PD before onset of motor symptoms, as well as a means to

Received Aug. 24, 2009; revised Sept. 4, 2009; accepted Sept. 8, 2009

A.V. is supported by a postdoctoral fellowship from the Edmond J. Safra Foundation. I thank Dr. Michel Modo for mentorship and editing and Dr. Nicholas Bray for insightful suggestions on the preparation of this manuscript.

Correspondence should be addressed to Dr. Anthony C. Vernon, Department of Neuroscience, King's College London, The James Black Centre, 125 Coldharbour Lane, London SE5 9NU,UK. E-mail: anthony.vernon@kcl.ac.uk.

D01:10.1523/JNEUROSCI.4156-09.2009

Copyright $\odot 2009$ Society for Neuroscience $\quad$ 0270-6474/09/2912842-03\$15.00/0 follow disease progression (Marek and Jennings, 2009).

Although loss of dopamine (DA) contributes to nonmotor symptoms in $\mathrm{PD}$, disruption of other neurotransmitter systems is also likely to be involved. Degeneration has been observed in noradrenergic (NA) and serotoninergic (5-HT) nuclei in $\mathrm{PD}$, in particular the locus ceruleus (LC) and raphe nucleus (Braak et al., 2003). Indeed, both NA and 5-HT are implicated in the development of depression and sleep disorders that are observed in PD patients (Chaudhuri and Schapira, 2009). Furthermore, positron emission tomography (PET) studies demonstrate clear deficits in both NA and 5-HT systems in PD patients, and these deficits correlate with development of nonmotor symptoms, particularly depression (Brooks, 2007). Together, these data suggest that $\mathrm{PD}$ is not only a dopaminergic disorder, but also involves deficits in other monoamine systems (Langston, 2006).

Classically, preclinical models of PD are generated using DA-selective neurotoxins, such as 6-hydroxydopamine (6-OHDA) or 1-methyl-4-phenyl-1,2,3,6-tetrahydropyridine (MPTP), which do not model deficits in other transmitter systems (Jenner, 2008). More recently, the neurotoxin rotenone has been used to model PD in rodents. Rotenone induces a general neuronal toxicity, affecting multiple systems, suggested to be more reminiscent of atypical parkinsonism (Jenner, 2008). Nonmotor phenotypes in neurotoxin-based models have not been extensively analyzed until re- cently, but increasing evidence suggests that nonmotor symptoms of $\mathrm{PD}$ are present in the 6-OHDA, MPTP, and rotenone models (Table 1). Crucially, however, these models do not show progressive, age-dependent neurodegeneration, which is particularly relevant to the etiology of PD (Jenner, 2008). Other animal models have been generated on the basis of genes identified in familial cases of PD, which mimic some aspects of $\mathrm{PD}$, including some nonmotor symptoms (Table 1). However, these are only partially successful in modeling the full neuropathological spectrum of the disease (Jenner, 2008). Thus, as yet there are still no genuinely progressive models that faithfully reproduce the cardinal features of PD (Jenner, 2008).

Within this context, Mooslehner et al. (2001) generated a mouse expressing $5 \%$ of normal levels of the vesicular monoamine transporter 2 (VMAT2), which regulates packaging of not only DA, but also NA and 5-HT into synaptic vesicles in neurons (Mooslehner et al., 2001). Caudle et al. (2007) characterize this mouse as a potential model of PD (Caudle et al., 2007). Indeed, VMAT2-deficient mice showed moderate, but progressive loss of the nigrostriatal dopamine system, $\alpha$-synuclein accumulation, and locomotor deficits (Caudle et al., 2007). In addition, VMAT2 deficiency resulted in substantial depletion of NA and 5-HT levels, allowing testing of whether these transmitter systems might underpin nonmotor symptoms in $\mathrm{PD}$. The recent article by Taylor et al. (2009) in The Journal of Neuroscience demonstrates that indeed, 
Table 1. Nonmotor phenotypes in preclinical PD models

\begin{tabular}{|c|c|c|c|c|c|c|}
\hline \multirow[b]{2}{*}{ Preclinical PD model } & \multicolumn{6}{|l|}{ Nonmotor phenotype } \\
\hline & GI dysfunction & Decreased sleep latency & Olfactory deficits & Anxiety/depressive behavior & Cognitive impairment & $\begin{array}{l}\text { Altered pain response/ } \\
\text { nociception }\end{array}$ \\
\hline Intrastriatal 6-OHDA & Not described & Not described & № (Tadaiesky et al., 2008) & $\begin{array}{l}\text { Yes (Branchi et al., 2008; } \\
\text { Tadaiesky et al., 2008) }\end{array}$ & $\begin{array}{l}\text { Yes (Ferro et al., 2005; } \\
\text { Tadaiesky et al., 2008) }\end{array}$ & $\begin{array}{l}\text { Yes (Tassorelli et al., 2007; } \\
\text { Chudler and Lu, 2008) }\end{array}$ \\
\hline MPTP (systemic) & $\begin{array}{l}\text { Yes (Anderson et al., } \\
\text { 2007) }\end{array}$ & $\begin{array}{l}\text { Yes (Monaca et al., 2004; } \\
\text { Barraud et al., 2009) }\end{array}$ & Yes (Prediger et al., 2009) & Yes (Vucković et al., 2008) & $\begin{array}{l}\text { Yes (Reksidler et al., 2007; } \\
\quad \text { Prediger et al., 2009) }\end{array}$ & Yes (Rosland et al., 1992) \\
\hline Rotenone (systemic) & $\begin{array}{l}\text { Yes (Drolet et al., 2009; } \\
\text { Greene et al., 2009) }\end{array}$ & Not described & Not described & Not described & Not described & Not described \\
\hline $\begin{array}{l}\alpha \text {-synuclein TG } \\
\quad \text { (PARK1, PARK4) }\end{array}$ & Not described & Not described & $\begin{array}{l}\text { Yes (Fleming et al., } \\
\text { 2008) }\end{array}$ & Yes (George et al., 2008) & Not described & Not described \\
\hline Parkin TG (PARK2) & Not described & Not described & Not described & Yes (Zhu et al., 2007) & Yes (Zhu et al., 2007) & Not described \\
\hline
\end{tabular}

VMAT2-deficient mice exhibit age-dependent phenotypes mimicking many of the nonmotor symptoms of PD (Taylor et al., 2009).

Taylor et al. (2009) first investigated the neurochemical deficits present in VMAT2-deficient mice. These animals showed substantial reductions in DA, NA, and 5-HT in the striatum, hippocampus, and cortex at 12-15 months of age, as well as increased metabolism of DA and 5-HT, compared with wild-type (WT) controls [Taylor et al. (2009), their Fig. 1].

The authors next characterized the behavioral manifestations of these neurochemical alterations in VMAT2-deficient and WT mice at different ages, using a range of tasks including tests of olfactory discrimination, sleep latency, gastrointestinal function, and anxiety/depressive phenotypes. Interestingly, VMAT2-deficient mice displayed progressive deficits in olfactory function from 5 months of age, which was not due to a problem in general sensory perception [Taylor et al. (2009), their Fig. 2, Fig. 4]. As in human PD, the authors report that this was not corrected by levodopa (L-DOPA) treatment. Consistent with previous reports in other rodent preclinical models of $\mathrm{PD}$, VMAT2-deficient mice also displayed a moderate decrease in gastric emptying [Taylor et al. (2009), their Fig. 6]. Young (4-6 month) VMAT2-deficient mice demonstrated decreased latency to sleep, compared with WT mice, a difference that became markedly less apparent with aging [Taylor et al. (2009), their Fig. 5]. Notably, VMAT2deficient mice also displayed clear anxiety and depressive-like phenotypes. Interestingly, these were also age dependent depending on the behavioral test [Taylor et al. (2009), their Fig. 7]. Indeed, young (4-6 months) but not old (12-15 months) VMAT2-deficient mice displayed a clear anxiety phenotype in the elevated plus maze. This is similar to the effects observed on sleep latency in VMAT2-deficient mice, leading the authors to suggest this may be due to a premature development of symptoms associated with normal aging. This hypothesis is supported by data demonstrating that VMAT2-deficient mice show statistically significant decreases in sleep latency and significantly increased time in the closed arms of the elevated plus maze at 4-6 months of age compared with age-matched controls, which is absent when older VMAT2-deficient mice (12-15 months) are compared with age-matched WT controls [Taylor et al. (2009), their Fig. 5A, Fig. 7A]. In addition, young (4-6 months) VMAT2deficient mice show significantly decreased latency to sleep compared with old (12-15 months) VMAT2-deficient mice [Taylor et al. (2009), their Fig. 5A]. In contrast, in the forced swim and tail suspension tests only old (12-15 months), but not young (4-6 months) VMAT2-deficient mice display a clear depressive phenotype [Taylor et al. (2009), their Fig. 7]. These data suggest anxiety behavior precedes depressive behavior in these animals. These data are somewhat representative of the clinical situation, although anxiety and depression frequently coexist in PD patients, even in the early stages of the disease (Aarsland et al., 2009). However, the spectrum of neuropsychiatric symptoms widens appreciably with advancing disease (Chaudhuri and Schapira, 2009).

The significance of this work compared with neurotoxin-based models that replicate some nonmotor symptoms of PD (Table 1), is that VMAT2-deficient mice show age-dependent and progressive onset of symptoms, as well as neurodegeneration of the nigrostriatal system and $\alpha$-synuclein pathology, thus more closely replicating the human disease (Caudle et al., 2007; Taylor et al., 2009). Importantly, some of the nonmotor phenotypes of VMAT2-deficient mice, including olfactory deficits, anxiety, and gastrointestinal abnormalities precede degenerative and motor behavioral changes in these animals, while others are manifest alongside motor symptoms, such as depression, as has been documented in PD pa- tients (Chaudhuri and Schapira, 2009). In addition, this model provides robust evidence that deficits in NA and 5-HT, as well as DA, may be involved in the development of PD nonmotor symptoms (Langston, 2006).

Importantly however, these mice do not allow identification of behavioral phenotypes related to deficits in individual monoamine neurotransmitter systems, since the data presented by Taylor et al. (2009) suggest that DA, 5-HT, and NA levels are equally affected by the global VMAT2 deficiency. Thus, the current study cannot distinguish whether individual monoamine neurotransmitter systems are important for the development of different nonmotor symptoms, or if a combined dysfunction is required. In addition, it is not clear at what age and in what brain regions the neurochemical deficits in DA, NA, and 5-HT are first present in VMAT2-deficient mice. Although data from the previous characterization of this model suggests alterations in DA metabolism are present from 6 months of age in VMAT2-deficient mice (Caudle et al., 2007), it is not clear whether other monoamine systems are perturbed at this time. This information could be useful for identifying intrinsic compensatory mechanisms as symptoms progress in these animals.

In their discussion, Taylor et al. (2009) cite unpublished evidence that extranigral neurodegeneration occurs in VMAT2deficient mice, including in the LC and raphe nucleus [Taylor et al. (2009), their Discussion]. A more extensive evaluation of these data would be valuable because it has been suggested that neurodegeneration in these nuclei precedes degeneration in the substantia nigra, and this may manifest clinically as nonmotor symptoms, including olfactory deficits (Braak et al., 2003). Specifically, it will be important to determine whether age-dependent, progressive degeneration occurs in these nuclei before nigral degeneration in VMAT2-deficient animals, and if so, 
whether such changes underlie nonmotor symptoms that are present before the onset of nigral degeneration. Furthermore, it would be informative to correlate changes in behavior with evolution of $\alpha$-synuclein pathology in the brains of VMAT2-deficient mice, because the onset of nonmotor symptoms is suggested to correlate with the progression of Lewy body (LB) pathology in PD (Braak et al., 2003).

Finally, other nonmotor characteristics of PD have not yet been explored in VMAT2-deficient mice. For example, cognitive dysfunction is a common feature of advanced PD, but may also be present before the onset of motor symptoms (WilliamsGray et al., 2007). It may therefore be interesting to examine whether VMAT2deficient mice display age-dependent cognitive deficits in behavioral paradigms such as the delayed matching to sample test using a T-maze. It is also not known whether VMAT2-deficient mice also display altered nociception or pain sensitivity. Importantly, DA can modulate pain in several CNS regions and unexplained or chronic pains are a significant component of the nonmotor complex of PD (Chaudhuri and Schapira, 2009). In addition, although the authors demonstrate that anxiety and depressive behavior in VMAT2-deficient animals were sensitive to antidepressant medication, it may be interesting to test whether these phenotypes are also sensitive to DA medication, as suggested in a human clinical trial (Chaudhuri and Schapira, 2009).

Nevertheless, this model, subject to further validation, may be a useful platform in which to evaluate the effects of DA and non-DA therapeutics on nonmotor symptoms of PD (Chaudhuri and Schapira, 2009). In addition, this model may offer a unique window of opportunity during which nonmotor symptoms and compensatory changes are present before the onset of motor symptoms and nigral neurodegeneration, in which to serially investigate biochemical, inflammatory, neuroimaging, and pathological changes in the brains of these animals. Importantly, this may shed light on mechanisms underlying both nonmotor and motor symptoms in PD, and may facilitate translational research aimed at identifying biomarkers for $\mathrm{PD}$, related to nonmotor symptoms.

\section{References}

Aarsland D, Brønnick K, Alves G, Tysnes OB, Pedersen KF, Ehrt U, Larsen JP (2009) The spec- trum of neuropsychiatric symptoms in patients with early untreated Parkinson's disease. J Neurol Neurosurg Psychiatry 80:928-930.

Anderson G, Noorian AR, Taylor G, Anitha M, Bernhard D, Srinivasan S, Greene JG (2007) Loss of enteric dopaminergic neurons and associated changes in colon motility in an MPTP mouse model of Parkinson's disease. Exp Neurol 207:4-12.

Barraud Q, Lambrecq V, Forni C, McGuire S, Hill M, Bioulac B, Balzamo E, Bezard E, Tison F, Ghorayeb I (2009) Sleep disorders in Parkinson's disease: the contribution of the MPTP non-human primate model. Exp Neurol 219:574-582.

Braak H, Del Tredici K, Rüb U, de Vos RA, Jansen Steur EN, Braak E (2003) Staging of brain pathology related to sporadic Parkinson's disease. Neurobiol Aging 24:197-211.

Branchi I, D’Andrea I, Armida M, Cassano T, Pèzzola A, Potenza RL, Morgese MG, Popoli P, Alleva E (2008) Nonmotor symptoms in Parkinson's disease: investigating early-phase onset of behavioral dysfunction in the 6-hydroxydopamine-lesioned rat model. J Neurosci Res 86:2050-2061.

Brooks DJ (2007) Imaging non-dopaminergic function in Parkinson's disease. Mol Imaging Biol 9:217-222.

Caudle WM, Richardson JR, Wang MZ, Taylor TN, Guillot TS, McCormack AL, Colebrooke RE, Di Monte DA, Emson PC, Miller GW (2007) Reduced vesicular storage of dopamine causes progressive nigrostriatal neurodegeneration. J Neurosci 27:8138-8148.

Chaudhuri KR, Schapira AH (2009) Non-motor symptoms of Parkinson's disease: dopaminergic pathophysiology and treatment. Lancet Neurol 8:464-474.

Chudler EH, Lu Y (2008) Nociceptive behavioral responses to chemical, thermal and mechanical stimulation after unilateral, intrastriatal administration of 6-hydroxydopamine. Brain Res 1213:41-47.

Drolet RE, Cannon JR, Montero L, Greenamyre JT (2009) Chronic rotenone exposure reproduces Parkinson's disease gastrointestinal neuropathology. Neurobiol Dis 36:96-102.

Ferro MM, Bellissimo MI, Anselmo-Franci JA, Angellucci ME, Canteras NS, Da Cunha C (2005) Comparison of bilaterally 6-OHDAand MPTP-lesioned rats as models of the early phase of Parkinson's disease: histological, neurochemical, motor and memory alterations. J Neurosci Methods 148:78-87.

Fleming SM, Tetreault NA, Mulligan CK, Hutson CB, Masliah E, Chesselet MF (2008) Olfactory deficits in mice overexpressing human wildtype alpha-synuclein. Eur J Neurosci 28: 247-256.

George S, van den Buuse M, San Mok S, Masters CL, Li QX, Culvenor JG (2008) Alpha-synuclein transgenic mice exhibit reduced anxiety-like behaviour. Exp Neurol 210:788-792.

Greene JG, Noorian AR, Srinivasan S (2009) Delayed gastric emptying and enteric nervous system dysfunction in the rotenone model of Parkinson's disease. Exp Neurol 218:154-161.

Jenner P (2008) Functional models of Parkinson's disease: a valuable tool in the develop- ment of novel therapies. Ann Neurol 64 [Suppl 2]:S16-S29.

Langston JW (2006) The Parkinson's complex: parkinsonism is just the tip of the iceberg. Ann Neurol 59:591-596.

Marek K, Jennings D (2009) Can we image premotor Parkinson disease? Neurology 72:S21-26.

Monaca C, Laloux C, Jacquesson JM, Gelé P, Maréchal X, Bordet R, Destée A, Derambure P (2004) Vigilance states in a parkinsonian model, the MPTP mouse. Eur J Neurosci 20:2474-2478.

Mooslehner KA, Chan PM, Xu W, Liu L, Smadja C, Humby T, Allen ND, Wilkinson LS, Emson PC (2001) Mice with very low expression of the vesicular monoamine transporter 2 gene survive into adulthood: potential mouse model for parkinsonism. Mol Cell Biol 21:5321-5331.

Prediger RD, Aguiar AS Jr, Rojas-Mayorquin AE, Figueiredo CP, Matheus FC, Ginestet L, Chevarin C, Bel ED, Mongeau R, Hamon M, Lanfumey L, Raisman-Vozari R (2009) Single intranasal administration of 1-methyl-4phenyl-1,2,3,6-tetrahydropyridine in $\mathrm{C} 57 \mathrm{BL} / 6$ mice models early preclinical phase of Parkinson's disease. Neurotox Res. Advance online publication. Retrieved July 21, 2009. doi:10.1007/s12640-009-9087-0.

Reksidler AB, Lima MM, Zanata SM, Machado HB, da Cunha C, Andreatini R, Tufik S, Vital MA (2007) The COX-2 inhibitor parecoxib produces neuroprotective effects in MPTPlesioned rats. Eur J Pharmacol 560:163-175.

Rosland JH, Hunskaar S, Broch OJ, Hole K (1992) Acute and long term effects of 1-methyl-4phenyl-1,2,3,6-tetrahydropyridine (MPTP) in tests of nociception in mice. Pharmacol Toxicol 70:31-37.

Tadaiesky MT, Dombrowski PA, Figueiredo CP, Cargnin-Ferreira E, Da Cunha C, Takahashi RN (2008) Emotional, cognitive and neurochemical alterations in a premotor stage model of Parkinson's disease. Neuroscience 156:830-840.

Tassorelli C, Armentero MT, Greco R, Fancellu R, Sandrini G, Nappi G, Blandini F (2007) Behavioral responses and Fos activation following painful stimuli in a rodent model of Parkinson's disease. Brain Res 1176:53-61.

Taylor TN, Caudle WM, Shepherd KR, Noorian A, Jackson CR, Iuvone PM, Weinshenker D, Greene JG, Miller GW (2009) Nonmotor symptoms of Parkinson's disease revealed in an animal model with reduced monoamine storage capacity. J Neurosci 29:8103-8113.

Vucković MG, Wood RI, Holschneider DP, Abernathy A, Togasaki DM, Smith A, Petzinger GM, Jakowec MW (2008) Memory, mood, dopamine, and serotonin in the 1-methyl-4phenyl-1,2,3,6-tetrahydropyridine-lesioned mouse model of basal ganglia injury. Neurobiol Dis 32:319-327.

Williams-Gray CH, Foltynie T, Brayne CE, Robbins TW, Barker RA (2007) Evolution of cognitive dysfunction in an incident Parkinson's disease cohort. Brain 130:1787-1798.

Zhu XR, Maskri L, Herold C, Bader V, Stichel CC, Güntürkün O, Lübbert H (2007) Non-motor behavioural impairments in parkin-deficient mice. Eur J Neurosci 26:1902-1911. 